\title{
Quality of Life among the Elderly patient with Urinary Incontinence: a Hospital Based Study at Assiut Governorate ,Egypt
}

\author{
Hoda Hanafy Shaker ${ }^{1}$, Safaa Ahmed Mohamed ${ }^{2}$, Ahmed S. Elazab ${ }^{3}$ \& Saieda Abd-El Hameed Abd-ELaziz ${ }^{4}$. \\ 1. Clinical demonstrator in Gerontological Nursing Department, Faculty of Nursing, Assiut University, Egypt. \\ 2. Professor of Community and Family Health Nursing Department, Faculty of Nursing, Assiut University, Egypt. \\ 3. Professor of Urology, Faculty of Medicine, Assiut University, Egypt. \\ 4. Lecturer of Gerontological Nursing Department, Faculty of Nursing, Assiut University, Egypt.
}

\begin{abstract}
Background: Urinary incontinence had adverse effects on quality of life among elderly subjects through both physical and psychosocial consequences and a significant impact on physical health and daily functioning. Study Aim: assess the quality of life among elderly patient with urinary incontinence. Subject $\&$ methods: A descriptive research design was used. the study was conducted in urology outpatient at Assiut university and El Eman general hospital. The total sample size was 395 elderly. Two tools were used. The $1^{\text {st }}$ tool: Interview questionnaire include personal characteristics, the $2^{\text {nd }}$ tool: Urogenital Distress Inventory and Adapted Incontinence Impact Questionnaires to assess quality of life among elderly patients with urinary incontinence. Results: $79.6 \%$ of elderly patients had unsatisfactory knowledge regarding UI. There was relationship between QOL \& urinary incontinence. It have a significant impact on the QOL for elderly patient. Conclusion: Urinary incontinence has significant negative impact on the QoL among elderly subjects (physical activity, social relationships/ travel, and emotional health). Recommendations: providing an Educational programs to increase the knowledge of the elderly patients about factors associated with urinary incontinence among the elderly people can guide actions to reduce and prevent occurrence of disease.
\end{abstract}

Key Words: Quality of Life, Elderly \& Patient, Urinary Incontinence.

\section{Introduction}

People worldwide are living longer. The number of older persons those aged 60 years or over is rising from 962 million globally in 2017 to 1.4 billion in 2030. By 2050, the world's population aged 60 years and older is expected to total 2 billion. (WHO, 2018). In Egypt the percent of older people "defined as 60 years of age and more" was $6.9 \%$ in 2015 . The percentage is projected to be $9.2 \%$ in 2021 , and it is expected to reach 20.8\% in 2050. (Egypt Demographics Profile 2018).

Urinary incontinence (UI) is a common health problem in senior population. UI is defined as any involuntary leakage of urine. ( Milsom et al., 2014). The World Health Organization (WHO) defines urinary incontinence as one of the "four giants" of geriatrics. Its prevalence and severity increase with age and comorbidity, urinary incontinence can severely affect quality of life, and its costs for society are high (WHO, 2014).

Urinary incontinence (UI) is widespread and well known disorder affecting millions of older adults. It is associated with a reduced quality of life (QOL), with sufferers reporting embarrassment, distress and depression. Yet some studies have found that those with UI considered urinary leakage as a minor problem and did not restrict daily activities or lower self-esteem (Serati, 2016).
Urinary incontinence affects more than 15 million people in the United States and approximately $30 \%$ to $40 \%$ of the population aged 75 and older. It can have adverse psychological, physical, and social effects, including skin breakdown, recurrent urinary tract infections, impaired sleep, falls and fractures, social withdrawal, anxiety, depression, and institutionalization (McLaren et al., 2015).

According to the World Health Organization(WHO), Quality of life is individuals' appreciation of their role in existence in the context of the culture in which they live and in relation to their goals, expectation requirements and worries, QoL includes dimensions: physical activity, social relationships, travel and emotional health. (WHO, 2018).

QoL includes dimensions: physical activity, social relationships, travel and emotional health.Urine leakage had bad impact on quality of life of elders', WHOQOL, depends on the subjective perception of the UI, and its treatment at social, physical and mental levels In general, women consider that UI has a greater impact on physical and social activities, trust and self perception and have a smaller impact on daily activities (WHOQOL, 2017).

\section{Significance of the study \\ Urinary Incontinence (UI) is a highly prevalent condition among Egyptian elderly people.}


Furthermore, overall prevalence of UI among Egyptian menopause women was $22.2 \%$ and The prevalence of stress urinary incontinence, urgency urinary incontinence and mixed urinary incontinence were $5.7 \%, 5.1 \%$ and $11.4 \%$, respectively (Bahloul et al., 2017).

Urinary incontinence can negatively affect the quality of life of older adult through both physical and psychosocial consequences and a significant impact on physical health and daily functioning, including social activities and emotional, work productivity, and sexual health and can lead to serious complication can increase mortality among older adult (Tatiana, 2017).

\section{Study Aim}

to assess the quality of life among elderly patients with urinary incontinence.

Study question: Is there a relationship between urinary incontinence and quality of life among elderly people?

\section{Subjects \& Methods}

Research design: Descriptive research design was used.

Setting: The study was carried out in outpatient urology clinic at Assiut university and El Eman general hospital .

Sample: Convenient sample were used for elderly patient with urinary incontinence (male \& female) and agreed to participate in the study. The total sample is 365 According to the prevalence rate of urinary incontinence among older adult that represent $(23.6 \%)$. by using software EPI /Info, version 3, 3 with $99 \%$ confidence interval $(\mathrm{CI})$. the estimated sample size found to be 365 patients, To compensate the drop outs, $10 \%$ was added to the sample size; the final sample size will be 395patients. The researchers taken all patients admitted to the urinary incontinence clinic 60 years, able to communicate and accept to participate in the study.

Study tools: data collected using 2 tools

Tool I: consisted of 3 parts

the $1^{\text {st }}$ part was included socio demographic data as, age, sex, residence, marital status, income, occupation, and level of education....etc. The $2^{\text {nd }}$ part: included past \& present history of urinary incontinence, presence of other chronic diseases or health problem as hypertension, diabetes, atherosclerosis and, Cardiovascular disease or other disease. The $3^{\text {rd }}$ part included patient's knowledge about urinary incontinence such as definition, signs \&symptoms, risk factors, medication and management of disease.
Tool II: Urogenital Distress Inventory and Adapted Incontinence Impact Questionnaires to assess the existence of urinary symptoms and the quality of life among elderly patients with urinary incontinence.

The Urogenital Distress Inventory(UDI): to assess the existence of urinary symptoms. It is consist of three subscale: the first irritative subscale $(\mathrm{Q} 1$ and Q2), the second stress subscale (Q3 and Q4) and the third discomfort subscale (Q5 and Q6) \& The adapted Incontinence Impact Questionnaires (IIQ): consist of eight items covering four domains : - Prayer (item 1): urinary leak disrupt your prayer schedule

-Physical activity (items 2 and 3): urinary leak affect your ability to do household activities (cooking, housecleaning), urinary leak affect your ability to do physical recreational activities as walking, swimming, or other exercises

-Social/Travel (items 4 and 5) : urinary leak affect your ability to do social activities outside your home (as visiting relatives and neighbors), urinary leak affect your ability to travel by bus or car for distance greater than $30 \mathrm{~min}$ away from home.

-Emotional health (items 6 and 7): urinary leak cause frustration experience, sense of low self-esteem and lost confidence, urinary leak affect your emotional health (nervousness, depression, etc. .. )

Scoring system: Questionnaires were scored such that a total score was assigned for the UDI if four or more of the six items were non missing and for the IIQ if five or more of the seven items were nonmissing. Each question has a 4-point response scale and patients were asked to rate the extent to which their UI affects their daily functioning $(0$, not at all; 1 , slightly; 2 , moderately; 3 , greatly) and submitted the total scores and subscales were converted to a $0-100$ scale and divided on $331 / 3$. The score of each item was summed-up and then was converted into percent score (less than 60\% unsatisfactory and $\geq 60 \%$ satisfactory)

Tools Validity

Tools tested for its content validity by group of three experts in the urology, community and gerontological health nursing. The required modifications were done.

Tools Reliability

Alpha Cronbach's test was used to assess internal consistency of tool and it was (Cronbach's $\alpha=0.72$ and 0.79 , for the UDI-6 and IIQ-7 respectively).

\section{Methods}

I- Preparatory stage: Official letter of endorsement was accomplished from the nursing faculty dean, to chiefs of urology hospital at Assiut university and director of El -Eman general hospital. The letter 
incorporated an endorsement to do the study, the nature and reason for the study.

II- Pilot study: The total sample is 395 Pilot study carried out prior starting of data collection on $(10 \%$ elderly), who excluded from the study. To test tools clarity and to assess the needed time for fulfilling it, the necessary modifications based on the result of pilot study and the questionnaire was reconstructed for ready to use.

III- Ethical Consideration: Nursing faculty ethical committee approved the research proposal. There was no risk for study subject during application of the research. Clinical research ethical principles was followed in the study. The right of refusing to participate to every elderly participants was assured and withdraw at any time from the study without any rational.

\section{VI- Field work:}

The elderly were met by the researcher, an explanation of the purpose of the research was done to participated in the study. Face to face individual interview with elderly was began, questionnaire were completed for all persons .

The researchers started to collect data in that period, three days weekly. Data collection was carried out at El- Eman general hospital from the first of April to the end of June, Assiut University hospital from the first of July to the end of December 2018 and the average number which interviewed was 3-4 elderly per day. The approximate time spent during the filling of sheet was around 30-45 minutes.

V- Statistical analysis: Data entry and data analysis were done using SPSS version 19 (Statistical Package for Social Science). Data were presented as number, percentage, mean, standard deviation. Chi-square test was used to compare between qualitative variables. Independent samples t-test was used to compare quantitative variables between two groups and ANOVA test was used for more than two groups. Pearson correlation was done to measure correlation between quantitative variables. P-value considered statistically significant when $\mathrm{P}<0.05$.

\section{Results}

Table (1): Distribution of the studied sample regarding their socio-demographic characteristics .

\begin{tabular}{|c|c|c|}
\hline Variables & No. & $\%$ \\
\hline \multicolumn{3}{|l|}{ Age: (years) } \\
\hline $60-<65$ & 130 & 32.9 \\
\hline $65-<70$ & 170 & 43.1 \\
\hline$\geq 70$ & 95 & 24.0 \\
\hline Mean \pm SD (Range) & \multicolumn{2}{|c|}{$66.63 \pm 5.74(60.0-95.0)$} \\
\hline \multicolumn{3}{|l|}{ Sex: } \\
\hline Male & 135 & 34.2 \\
\hline Female & 260 & 65.8 \\
\hline \multicolumn{3}{|l|}{ Patient education: } \\
\hline Illiterate & 103 & 26.1 \\
\hline Read \& write & 164 & 41.5 \\
\hline Primary & 62 & 15.7 \\
\hline Preparatory & 30 & 7.6 \\
\hline Secondary & 24 & 6.1 \\
\hline University & 12 & 3.0 \\
\hline \multicolumn{3}{|l|}{ Occupation before retirement: } \\
\hline Employee & 102 & 25.8 \\
\hline Worker & 26 & 6.6 \\
\hline Farmer & 26 & 6.6 \\
\hline Free business & 44 & 11.1 \\
\hline Skilled worker & 24 & 6.1 \\
\hline Housewife & 173 & 43.8 \\
\hline \multicolumn{3}{|l|}{ Current occupation: } \\
\hline Unemployed & 42 & 10.7 \\
\hline Farmer & 25 & 6.3 \\
\hline Free business & 65 & 16.4 \\
\hline Skilled worker & 19 & 4.8 \\
\hline Housewife & 244 & 61.8 \\
\hline
\end{tabular}




\begin{tabular}{|l|c|c|}
\hline \multicolumn{1}{|c|}{ Variables } & No. & \% \\
\hline Residence: & & 68.9 \\
\hline Rural & 272 & 31.1 \\
\hline Urban & 123 & 30.9 \\
\hline Social class: & & 48.6 \\
\hline Low & 122 & 20.5 \\
\hline Middle & 192 & \\
\hline High & 81 & 14.4 \\
\hline Residential state: & & 85.6 \\
\hline Alone & 57 & 338 \\
\hline With family & & \\
\hline
\end{tabular}

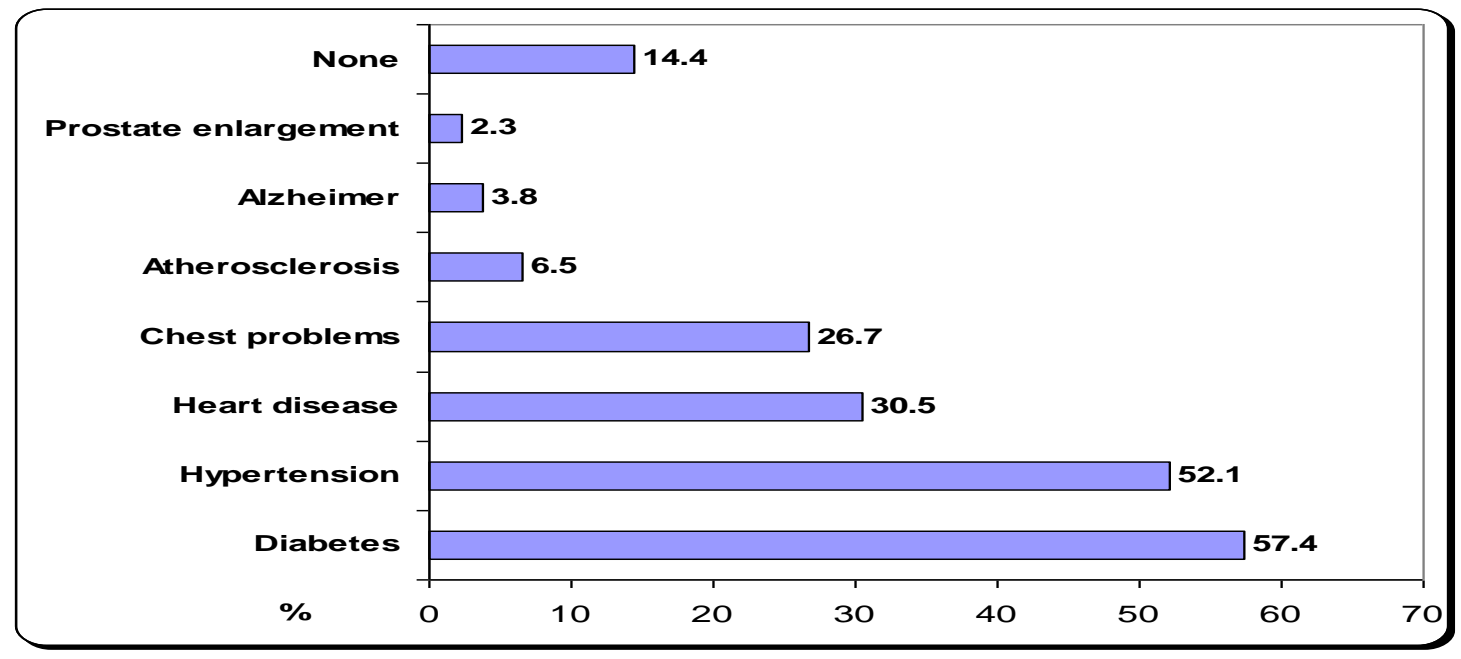

Figure (1): Distribution of the studied sample according to their health history of chronic diseases.

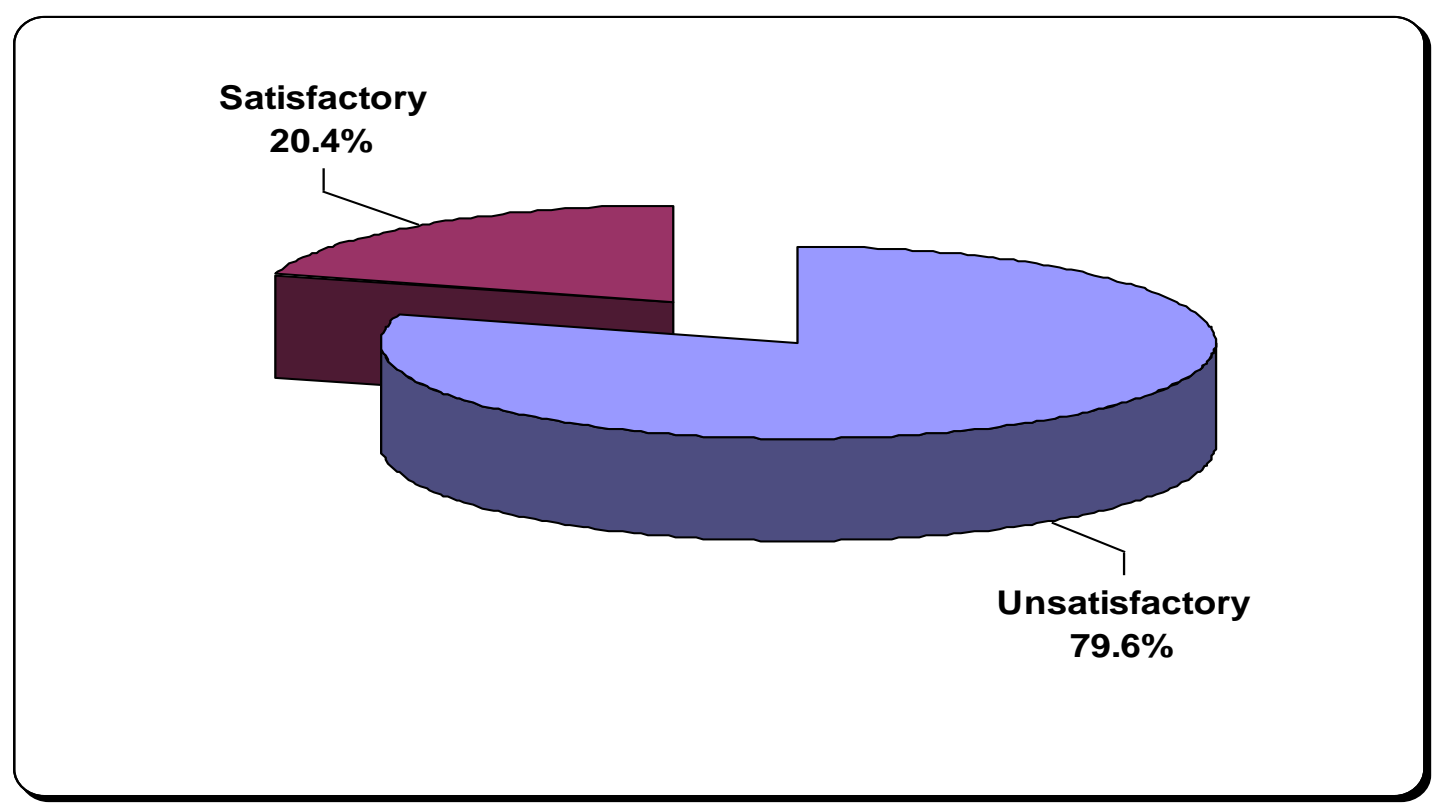

Figure (2): Distribution of the studied sample according to their score of knowledge about urinary incontinence. 
Table (2): Relation between level of knowledge and socio demographic data among the studied sample with urinary incontinence .

\begin{tabular}{|c|c|c|c|c|c|}
\hline \multirow{3}{*}{ Variables } & \multicolumn{4}{|c|}{ Knowledge level } & \multirow{3}{*}{ P-value } \\
\hline & \multicolumn{2}{|c|}{ Unsatisfactory } & \multicolumn{2}{|c|}{ Satisfactory } & \\
\hline & No. & $\%$ & No. & $\%$ & \\
\hline \multicolumn{5}{|l|}{ Age:(years) } & \multirow{4}{*}{0.588} \\
\hline $60-<65$ & 101 & 77.7 & 29 & 22.3 & \\
\hline $65-<70$ & 134 & 78.8 & 36 & 21.2 & \\
\hline$\geq 70$ & 79 & 83.2 & 16 & 16.8 & \\
\hline \multicolumn{5}{|l|}{ Sex: } & \multirow{3}{*}{0.077} \\
\hline Male & 115 & 84.6 & 21 & 15.4 & \\
\hline Female & 200 & 77.2 & 59 & 22.8 & \\
\hline \multicolumn{5}{|l|}{ Patient education: } & \multirow{5}{*}{$0.000 *$} \\
\hline Illiterate & 92 & 87.6 & 13 & 12.4 & \\
\hline Read \& write & 146 & 89.0 & 18 & 11.0 & \\
\hline Basic education & 62 & 68.9 & 28 & 31.1 & \\
\hline Secondary/ university & 14 & 38.9 & 22 & 61.1 & \\
\hline \multicolumn{5}{|l|}{ Residence: } & \multirow{3}{*}{$0.000 *$} \\
\hline Rural & 231 & 84.9 & 41 & 15.1 & \\
\hline Urban & 83 & 67.5 & 40 & 32.5 & \\
\hline \multicolumn{5}{|l|}{ Social class } & \multirow{4}{*}{$0.000 *$} \\
\hline Low & 102 & 83.6 & 20 & 16.4 & \\
\hline Middle & 178 & 92.7 & 14 & 7.3 & \\
\hline High & 36 & 43.4 & 47 & 56,6 & \\
\hline
\end{tabular}

*There is significant difference - Significant at $P<0.05$

Table (3): Relation between quality of life domains and knowledge level among the studied sample with urinary incontinence.

\begin{tabular}{|l|c|c|c|}
\hline \multirow{2}{*}{\multicolumn{1}{|c|}{ Variables }} & \multicolumn{2}{c|}{ Knowledge level } & \multirow{2}{*}{ P-value } \\
\cline { 2 - 4 } & Unsatisfactory & Satisfactory & \\
\cline { 2 - 4 } & Mean \pm SD & Mean \pm SD & \\
\hline Prayer schedule & $68.57 \pm 31.37$ & $71.19 \pm 29.23$ & 0.496 \\
\hline Physical activity & $61.86 \pm 30.06$ & $70.16 \pm 29.43$ & $\mathbf{0 . 0 2 7} *$ \\
\hline Social/ relationships/ travel & $70.41 \pm 21.64$ & $72.42 \pm 16.70$ & 0.435 \\
\hline Emotional health & $66.19 \pm 19.53$ & $72.42 \pm 16.06$ & $\mathbf{0 . 0 0 8} *$ \\
\hline IIQ-7 & $66.49 \pm 18.22$ & $71.60 \pm 14.76$ & $\mathbf{0 . 0 2 0} *$ \\
\hline
\end{tabular}

*There is significant difference - Significant at $P<0.05$

Table (4): Relation between total quality of life domains and risk factor among the studied sample with urinary incontinence.

\begin{tabular}{|l|c|c|}
\hline \multicolumn{1}{|c|}{ Variables } & IIQ-7 & \multirow{2}{*}{ P-value } \\
\cline { 2 - 3 } & & Mean \pm SD \\
\hline Suffering from urinary tract disorders: & & \multirow{2}{*}{0.192} \\
\hline Yes & $66.18 \pm 17.68$ & \multirow{2}{*}{0.186} \\
\hline No & $68.52 \pm 17.64$ & \\
\hline Suffering from urinary tract infection: & & \multirow{2}{*}{0.111} \\
\hline Yes & $70.14 \pm 16.71$ & 0.11 \\
\hline No & $67.01 \pm 17.84$ & \\
\hline Suffering from constipation: & & \\
\hline Yes & $68.80 \pm 17.69$ & \\
\hline No & $65.96 \pm 17.58$ & \\
\hline
\end{tabular}




\begin{tabular}{|c|c|c|}
\hline \multirow{2}{*}{ Variables } & IIQ-7 & \multirow{2}{*}{ P-value } \\
\hline & Mean \pm SD & \\
\hline \multicolumn{2}{|l|}{$\begin{array}{l}\text { Symptoms of urinary incontinence become worse since } \\
\text { weight gain: }\end{array}$} & \multirow{3}{*}{0.230} \\
\hline Yes & $68.17 \pm 17.67$ & \\
\hline No & $65.74 \pm 17.65$ & \\
\hline \multicolumn{2}{|l|}{ Current smoking: } & \multirow{3}{*}{$0.000 *$} \\
\hline Yes & $57.82 \pm 16.27$ & \\
\hline No & $69.87 \pm 17.22$ & \\
\hline \multicolumn{2}{|l|}{ Taking stimuli: } & \multirow{3}{*}{$0.000^{*}$} \\
\hline Yes & $63.27 \pm 18.43$ & \\
\hline No & $72.09 \pm 15.63$ & \\
\hline \multicolumn{2}{|l|}{ Suffering from hearing loss: } & \multirow{3}{*}{0.457} \\
\hline Yes & $66.54 \pm 19.81$ & \\
\hline No & $67.98 \pm 16.66$ & \\
\hline
\end{tabular}

*There is significant difference - Significant at $P<0.05$

Table (5): Relation between total quality of life domains and chronic disease among the studied sample with urinary incontinence .

\begin{tabular}{|c|c|c|}
\hline \multirow{2}{*}{ Chronic disease } & IIQ-7 & \multirow{2}{*}{ P-value } \\
\hline & Mean \pm SD & \\
\hline \multicolumn{2}{|l|}{ Diabetes: } & \multirow{3}{*}{0.311} \\
\hline Yes & $68.31 \pm 18.23$ & \\
\hline No & $66.49 \pm 16.89$ & \\
\hline \multicolumn{2}{|l|}{ Hypertension: } & \multirow{3}{*}{$0.020^{*}$} \\
\hline Yes & $65.56 \pm 17.66$ & \\
\hline No & $69.69 \pm 17.48$ & \\
\hline \multicolumn{2}{|l|}{ Heart disease: } & \multirow{3}{*}{$0.042^{*}$} \\
\hline Yes & $64.81 \pm 18.64$ & \\
\hline No & $68.73 \pm 17.13$ & \\
\hline \multicolumn{2}{|l|}{ Chest problems: } & \multirow{3}{*}{$0.000 *$} \\
\hline Yes & $58.22 \pm 16.31$ & \\
\hline No & $70.93 \pm 16.94$ & \\
\hline
\end{tabular}

*There is significant difference - Significant at $P<0.05$

Table (6): Relation between quality of life domains and knowledge level in urinary incontinence patients .

\begin{tabular}{|l|c|c|c|}
\hline \multirow{2}{*}{\multicolumn{1}{|c|}{ Variables }} & \multicolumn{2}{c|}{ Knowledge level } & \multirow{2}{*}{ P-value } \\
\cline { 2 - 3 } & Unsatisfactory & Satisfactory & \\
\cline { 2 - 3 } & Mean \pm SD & Mean \pm SD & \\
\hline Prayer schedule & $68.57 \pm 31.37$ & $71.19 \pm 29.23$ & 0.496 \\
\hline Physical activity & $61.86 \pm 30.06$ & $70.16 \pm 29.43$ & $0.027^{*}$ \\
\hline Social/ relationships/ travel & $70.41 \pm 21.64$ & $72.42 \pm 16.70$ & 0.435 \\
\hline Emotional health & $66.19 \pm 19.53$ & $72.42 \pm 16.06$ & $0.008^{*}$ \\
\hline IIQ-7 & $66.49 \pm 18.22$ & $71.60 \pm 14.76$ & $0.020^{*}$ \\
\hline
\end{tabular}

There is significant difference at $P<0.05$ 


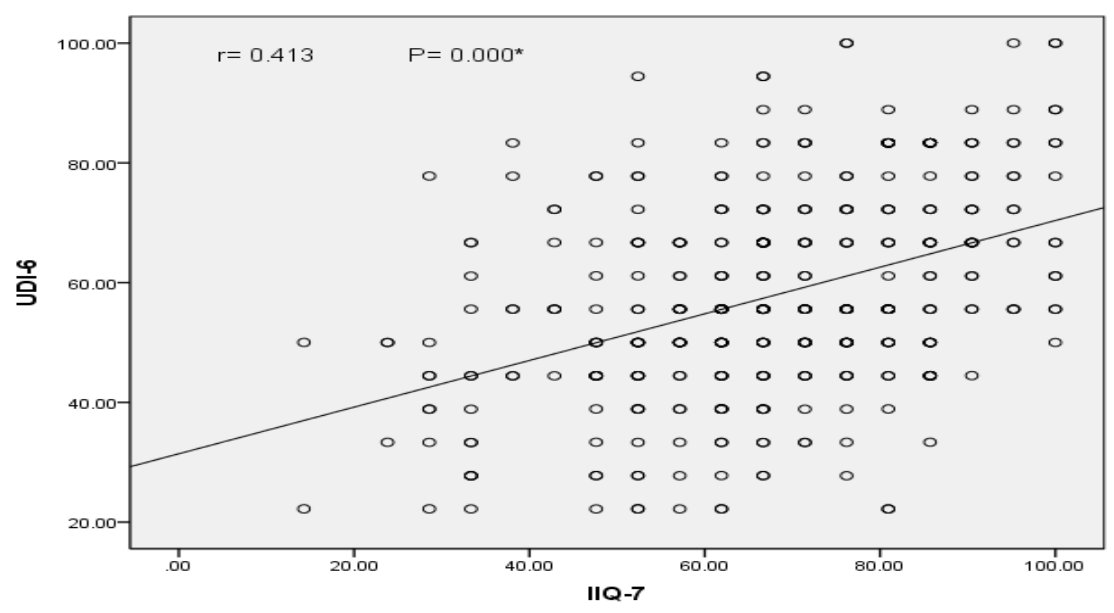

Figure (3): Correlation between total quality of life domains and total Urogenital Distress Inventory score among the studied sample with urinary incontinence .

\section{5 elderly subjects (60 years and more)accepted to participate in the study.}

Table (1): Illustrated that $32.9 \%$ of the studied patients aged $(60<65)$ years, while $43.1 \%$ of them aged $(65<70)$ years and $24.0 \%$ of them aged $(70)$ or older the mean age was \pm SD $66.63 \pm 5.74$. Regarding to sex, it was observed that $34.2 \%$ of the studied participants were male, while $65.8 \%$ of them were female. Also the table showed that $68.9 \%$ of the participants live in rural areas while $31.1 \%$ of them live in urban areas.

Figure (1): Showed that $57.4 \%$ of the studied sample had history of diabetes, while $52.1 \%, 30.5 \%$ respectively had history for hypertension and heart disease.

Figure (2): Demonstrated that $79.6 \%$ of the studied sample had unsatisfactory score of knowledge, while $20.4 \%$ of them had satisfactory score of knowledge.

Table (2): Cleared that there was a statistical significant difference between knowledge level of the studied sample with patient's education, and residence and social class with $\mathrm{P}=0.000$. Also this table illustrated that there was no significant difference between level of knowledge of the studied sample with age and sex with $\mathrm{P}=0.588, \mathrm{P}=0.077$ respectively.

Table (3): Revealed that the high mean score was founded in social/ relationships/ travel domain and low mean score was found in physical activity domain. There was statistical significant difference between studied samples as regard physical activity, emotional health and knowledge level $(\mathrm{P}=0.027$, 0.008).Also there was statistical significant difference between total QOL and knowledge level $(\mathrm{P}=0.020)$

Table (4): Presented there was a statistical significant difference between total quality of life of the studied sample with smoking and taking stimuli with $\mathrm{P}=$ $0.020, \mathrm{P}=0.000, \mathrm{P}=0.000$ respectively. Also there was no a significant difference between total quality of life of the studied sample with UTI, constipation, weight gain and hearing loss with $\mathrm{P}=0.186, \mathrm{P}=0.111$, $\mathrm{P}=0.230, \mathrm{P}=0.457$ respectively.

Table (5): presented there was a significant difference between total quality of life of the studied sample with hypertension, heart disease and chest problem $\mathrm{P}=0.020, \mathrm{P}=0.042, \mathrm{P}=0.000$ respectively and there was no a significant difference between total quality of life of the studied sample with diabetes $\mathrm{P}=0.311$.

Table (6): presented there was a significant difference between studied samples as regard physical activity, emotional health and knowledge level $(\mathrm{P}=0.027,0.008)$. Also there was a statistical significant difference between total QOL domains mean score and knowledge level $\mathrm{P}=0.020$.

Figure (3): showed that there was positive correlation between total quality of life domains and urogenital distress inventory(UDI) $(r=0.413)$.

\section{Discussion}

Urinary incontinence (UI) is widespread and well known disorder affecting millions of older adults with prevalence ranging from 17 to $55 \%$ in older women and $11-34 \%$ in older men. UI imposes a significant financial burden to affected individuals, caregivers and society. In the USA, the annual cost of urinary incontinence was 26.3 billion dollars for persons aged 65 years and more. It is attributed with a poor quality of life (QOL), with sufferers reporting embarrassment, depression, distress and lower selfesteem ( Goepel, et, al., 2016).

The present study showed that urinary incontinence increase with age as more than two fifth of the studied sample aged from $(65<70)$ years old, this could be attributed to normal aging changes in 
urinary anatomy and patho-physiology, which allows incontinence to occur more easily. Aging results in the reduced size of the urinary bladder, producing a decreased bladder volume and a need for more frequent bladder emptying (urinary frequency), the mean age of the studied sample was $66.63 \pm 5.74$, this is similar to Ateskan et al., (2018) who reported that age was found to be associated with urinary Incontinence $54.7 \%$ of the study participants were in age from $65-70$ years with mean age $69.7 \pm 6.8$ years. The current study revealed that urinary incontinence more common in females than males as about two third of the studied sample were female affected by UI, this may be related to previous number of pregnancies of elderly female before aging, this is similar to study done by Larissa et al., (2015) who reported that $63.9 \%$ of the studied population were female. While this disagree with Layse et al., (2015) who founded that urinary incontinence more prevalent in males than females.

Concerning to level of education, it was apparent that urinary incontinence was prevalent among illiterate \& only read and write participants as more than one quarter of the studied sample were illiterate and more than two fifth of them were only read and write. This related to that educated people seeking help as early as possible in reverse to illiterate ones. This is similar to Ateskan et al., (2018) who founded that UI was more prevalent among illiterate elderly people or could only read and write as $44.8 \%$ of the studied elderly were illiterate $\& 49.3 \%$ of them only read and write.

Relating to chronic diseases associated with urinary incontinence among the studied sample, the present study illustrated that less than one third of the studied sample had heart disease, this may be related to that the aging process and multifunctional body system impairments which increase the risk of urinary incontinence. and this may be as a result of complication of chronic illness after a long period, this agree with Aslan et al., (2017) who stated that heart failure and acute chronic diseases, common health problems in the elderly, will cause urinary incontinence. More over this agree with O'Donnell et al., (2017) who reported that urinary incontinence was more frequent among older patients with heart disease.

The present study showed that the majority of the studied sample had unsatisfactory score of knowledge regarding urinary incontinence, while only one fifth of them had satisfactory score of knowledge, this may be as people age learning skills and cognitive function decline. This similar to findings reported by Laurence et al., (2015) who founded that there was substantial gaps in the knowledge of older persons about urinary incontinence.
According to relationship between knowledge level of elderly participants and their age groups it was cleared that there was no statistical significant difference between age and knowledge level of elderly participants $\mathrm{P}=0.588$, this disagree with Marciane et al., (2018) who founded that there was statistical significant difference between age and knowledge level of elderly participants $\mathrm{P}=0.001$.

Also the present study noticed that there was statistical significant difference between educational status of elderly participants and their knowledge level $\mathrm{P}=0.000$, this may be because of that well educated elderly people had good awareness and health information regarding their disease as urinary incontinence. This agree with Marciane et al., (2018) who reported that schooling years of elderly participants and their knowledge level $\mathrm{P}=0.002$.

Concerning to relationship between quality of life (QOL) domains mean score among the studied sample and physical activity status it was illustrated that physical activity domain achieved lowest mean score $63.56 \pm 30.08$ followed by emotional domain $67.46 \pm 19.02$, this may be due to urinary incontinence act as a barrier of physical activities. This agree with Muhammet et al., (2014) who reported that physical activity domain achieved lowest mean score $34.7 \pm 2.7$ followed by emotional domain $46.4 \pm 2.6$.

Concerning to relationship between risk factors of urinary incontinence among elderly studied participants and their total quality of life mean score it was cleared that there was a statistical significant difference between total quality of life of the studied sample with their smoking status $\mathrm{P}=0.000$, this was similar to study done by Larissa et al., |(2015) who founded that there was a statistical significant difference between total quality of life of the studied sample with their smoking status $\mathrm{P}=0.070$.

Also the present study revealed that there was no a statistical significant difference between total quality of life of the studied sample and other risk factors as urinary tract infection, constipation, and weight gain $\mathrm{P}=0.186, \mathrm{P}=0.111$, \& $\mathrm{P}=0.230$ respectively, this agree with Larissa et al., (2015) who reported that there was a statistical significant difference between total quality of life of the studied sample and other risk factors as urinary tract infection, constipation, and $\mathrm{BMI} \mathrm{P}=0.001 \mathrm{P}=0.017, \& \mathrm{P}=0.000$.

Furthermore, the current study showed there was statistical significant effect between total quality of life of elderly participants and their chronic conditions as heart diseases and chest problems $\mathrm{P}=$ $0.042 \& \mathrm{P}=0.000$ respectively, this was similar to findings reported by Ateskan et al., (2018) who founded that there was statistical significant effect between total quality of life of elderly participants 
and heart diseases and respiratory problems $\mathrm{P}=0.014$ $\& \mathrm{P}=0.032$ respectively.

Regarding to relationship between knowledge level of elderly studied participants and their total quality of life mean score it was presented that there was statistical significant difference between total quality of life domain mean score and elders' knowledge level $\mathrm{P}=0.020$, this indicate that as elderly people had satisfactory level of knowledge as they had high quality of life. This agree with Mourão et al., (2018) who study Association Between Knowledge and Attitude About Aging and Life Satisfaction Among Older Koreans and founded that positive relationship was found between knowledge level and quality of life $\mathrm{P}=0.001$.

\section{Conclusion}

Urinary incontinence is a frequent condition among elderly and elevated with age and common in female than male, also elderly people who had low educational level and came from rural areas achieved unsatisfactory knowledge level. Urinary incontinence worsen quality of life and had a significant effect on the domain quality of life score (physical activity, social relationships/ travel, and emotional health).

\section{Recommendations}

- Screening for all people above the age of 60 years for early detection of urinary incontinence.

- Designed programs should provided to elderly to increase their knowledge about factors attributed with urinary incontinence as: causes, risk factors, treatment, and complications of urinary incontinence can guide actions to reduce and prevent occurrence of disease.

- Health professionals training regarding evaluation methods of incontinence, early diagnosis, also risk factors knowledge is urgently needed.

\section{References}

1. Bahloul Mustafa, Ahmed M., Abbas, Mervat A., Abo-Elhagag, Elwani Elsnosy, Alaa-eldein A., Youssef Bahloul M., (2017): Prevalence of overactive bladder symptoms and urinary incontinence in a tertiary care hospital in Egypt. International Journal of Reproduction, Contraception, Obstetrics and Gynecology Vol.6(6), Page 2133.

2. Egypt Demographics Profile (2018): Aging. Available https://www.indexmundi.com/egypt/demographic s_profile.html.

3. Goepel M., Hoffmann J., \& Piro M., (2016): Prevalence and physician awareness of symptoms of urinary bladder dysfunction. Eur Urol.Vol.41(3), Pp:234-239.

4. Larissa Pruner Marques I., Ione Jayce Ceola Schneider I., Maruí Weber Corseuil GiehlI, Danielle Ledur AntesI, \& Eleonora d'OrsiI. M., (2015): Demographic, health conditions, and lifestyle factors associated with urinary incontinence in elderly from Florianópolis, Santa Catarina, Brazil REV BRAS EPIDEMIOL JULSEP. Vol.18(3), Pp: 595-606.

5. Laurence G., Branch Laura A., Walker Catherine E., DuBeau Neil M., Resnick, (2015): Urinary Incontinence Knowledge Among Community-Dwelling People 65 Years of Age and Older, American Geriatrics society journal Volume42, Issue12 Pages 1257-1261

6. Layse Quadros L., Aguiar A., Menezes A., Alves E., Nery T., Bezerra P., (2015): Prevalence of urinary incontinence among institutionalized elderly and its relationship to mental state, functional independence, and associated comorbidities Acta Fisiatr.Vol.22(3), Pp:130-134.

7. Marciane K., Luiz A., Facchini M., Uhlmann S., \& Bruno P., (2018): Prevalence of urinary incontinence among the elderly and relationship with physical and mental health indicators a of Bagé, Rio Grande do Sul, Brazil Rev. Bras. Geriatr. Gerontol., Rio de Janeiro, Vol. 21(4), Pp: 397-407.

8. McLaren S., McPherson F., Sinclair F., \& Ballinger B., (2015): Prevalence and severity of incontinence among hospitalized, female psychogeriatric patients. HealthBull. Vol.39(3), Pp:157-161.

9. Milsom I., Coyne K., Nicholson S., Kvasz M., Chen C., Wein A., (2014): Global prevalence and economic burden of urgency urinary incontinence: a systematic review. Eur Urol ; Vol.65, Pp: 79-95.

10. Muhammet Guzelsoy, Hakan Demirci, Soner Coban, Buket Belkiz Gungor, Emin Ustunyurt, Serhat Isildak (2014): Impact of Urinary Incontinence on Quality of Life among Residents Living in Turkey Vol. 11(2), Pp:1447-1451.

11. Mourão F., Lopes L., Vasconcellos N., \& Almeida M., (2018): Prevalência de queixas urinárias e o impacto destas na qualidade de vida de mulheres integrantes de grupos de atividade física. Acta Fisiatr; 15(3): Pp:170-75.

12. Serati M., (2016): Incontinence among elderly people. Proceedings of First National Symposium On Gerontology.; Fisioter Pesq.Vol.5(8), Pp:165172.

13. Aslan E., Kizilkaya Beji N., Ayyildiz Erkan H., Yalçin Ö (2017); The Impact on the quality of the 
life and prevalence of urinary and fecal incontinence of elderly people in nursing home residents. Huzurevlerinde kalan yaplý bireylerin üriner ve fekal inkontinans prevalansý ve yapam kalitesi üzerine etkisi (Turkish). Available at: http://

www.urojinekolojidernegi.org/ulusal/17.GIF

14. Ateskan Ü., Mas M., Doruk H., Kutlu M., (2018): Urinary incontinence among the elderly people of Turkey: Prevalence, clinical types and health-care seeking. Geriatrics (Turkish);3(2):4550.

15. O’Donnell M., Lose G., Sykes D., Voss S., Hunskaar S., (2017): Helping-Seeking Behavior and Associated Factors among Women with Urinary Incontinence in France, Germany, Spain and the United Kingdom. European Urology;47:385-92.

16. Tatiana V., (2017): The Relationship Between Urinary Incontinence, Mobility Limitations, and Disability in Older Women.

17. World Health Organization (2018): https://www.who.int/news-room/factsheets/detail/ageing-and-health.

18. WHO, (2014): Ageing and life course, Available at http://www.who.int/ageing/projects/age_friendly_ standards/en/

19. WHOQOL,(2017): The world health organization quality of life assessment (WHOQOL): position paper from the World Health Organization. Soc Sci Med.;41(10):14039. 